\title{
The discovery of insulin revisited: lessons for the modern era
}

\author{
Gary F. Lewis and Patricia L. Brubaker \\ Department of Medicine, Department of Physiology, and Banting and Best Diabetes Centre, University of Toronto, Toronto, Ontario, Canada.
}

\begin{abstract}
2021 to 2022 marks the one hundredth anniversary of ground-breaking research in Toronto that changed the course of what was, then, a universally fatal disease: type 1 diabetes. Some would argue that insulin's discovery by Banting, Best, Macleod, and Collip was the greatest scientific advance of the 20th century, being one of the first instances in which modern medical science was able to provide lifesaving therapy. As with all scientific discoveries, the work in Toronto built upon important advances of many researchers over the preceding decades. Furthermore, the Toronto work ushered in a century of discovery of the purification, isolation, structural characterization, and genetic sequencing of insulin, all of which influenced ongoing improvements in therapeutic insulin formulations. Here we discuss the body of knowledge prior to 1921 localizing insulin to the pancreas and establishing insulin's role in glucoregulation, and provide our views as to why researchers in Toronto ultimately achieved the purification of pancreatic extracts as a therapy. We discuss the pharmaceutical industry's role in the early days of insulin production and distribution and provide insights into why the discoverers chose not to profit financially from the discovery. This fascinating story of bench-to-beside discovery provides useful considerations for scientists now and in the future.
\end{abstract}

In the words of the late historian Professor Michael Bliss, "The discovery of insulin at the University of Toronto in 1921-1922 was one of the most dramatic events in the history of the treatment of disease. Insulin's impact was so sensational because of the incredible effect it had on diabetic patients. Those who watched the first starved, sometimes comatose, [patients with diabetes] receive insulin and return to life saw one of the genuine miracles of modern medicine. They were present at the closest approach to the resurrection of the body that our secular society can achieve, and at the discovery of what has become the elixir of life for millions of human beings around the world" (1).

In this Review, published 100 years after the discovery of insulin at the University of Toronto, we briefly discuss the history of the discovery, with a focus on the key players, the scientific advancements that enabled the bedside implementation of this bench discovery, and a number of ramifications of that momentous discovery. Interesting questions and discussion points abound. What was the body of knowledge prior to 1921 that localized insulin to the pancreas and established a role for insulin in glucoregulation, and why was the ultimate purification of insulin as a lifesaving therapy accomplished by researchers in Toronto? What was the role of the pharmaceutical industry in the early days of insulin production and distribution? Why did the discoverers choose not to profit financially from the discovery? And, finally, does this early story of benchto-beside discovery provide useful considerations for scientists not only in the present but also in the future?

Conflict of interest: The authors have declared that no conflict of interest exists. Copyright: (c) 2021, American Society for Clinical Investigation.

Reference information: J Clin Invest. 2021;131(1):e142239.

https://doi.org/10.1172/JCl142239.
A particularly memorable aspect of the discovery of insulin is a note that Dr. Frederick Banting, a general surgeon struggling to start a new practice in London, Ontario, Canada (a city approximately $200 \mathrm{~km}$ west of Toronto) and with no prior research experience, jotted down at 2 am one night in the autumn of 1920, shortly after reading an article about the pancreas for an upcoming lecture in anatomy: "Ligate pancreatic ducts of dog. Keep dogs alive till acini degenerate leaving Islets. Try to isolate the internal secretion of these to relieve glycosurea [sic]" $(1,2)$. His hypothesis that atrophy of pancreatic acini following pancreatic duct ligation would prevent proteolytic degradation of the putative "internal secretion" was not entirely original and, in any case, turned out to be incorrect; nevertheless, Banting's interest in the topic set the ball in motion for the ultimate purification and manufacture of insulin not only as a lifesaving treatment for patients with type 1 diabetes, but also as an effective therapeutic in many with type 2 diabetes.

\section{Early work leading to insulin's discovery}

An extensive review of the many scientific contributions that set the stage for the isolation and purification of insulin in Toronto in 1921-1922 is beyond the scope of this Review article. However, as with virtually all research, the discovery was based, in part, on a body of scientific knowledge that well preceded the Toronto work (Figure 1). It began with Paul Langerhans's discovery in 1869 of clusters of cells in the pancreas (now known as the islets of Langerhans) that appeared to be floating in the more abundant pancreatic acini, and that were not connected to the pancreatic duct, which drained the exocrine pancreatic secretions into the duodenum (3). Additionally, over the ensuing three decades, researchers localized a critical factor to the pancreas that controls the body's utilization of fuels, the absence or deficiency of which led to diabetes 


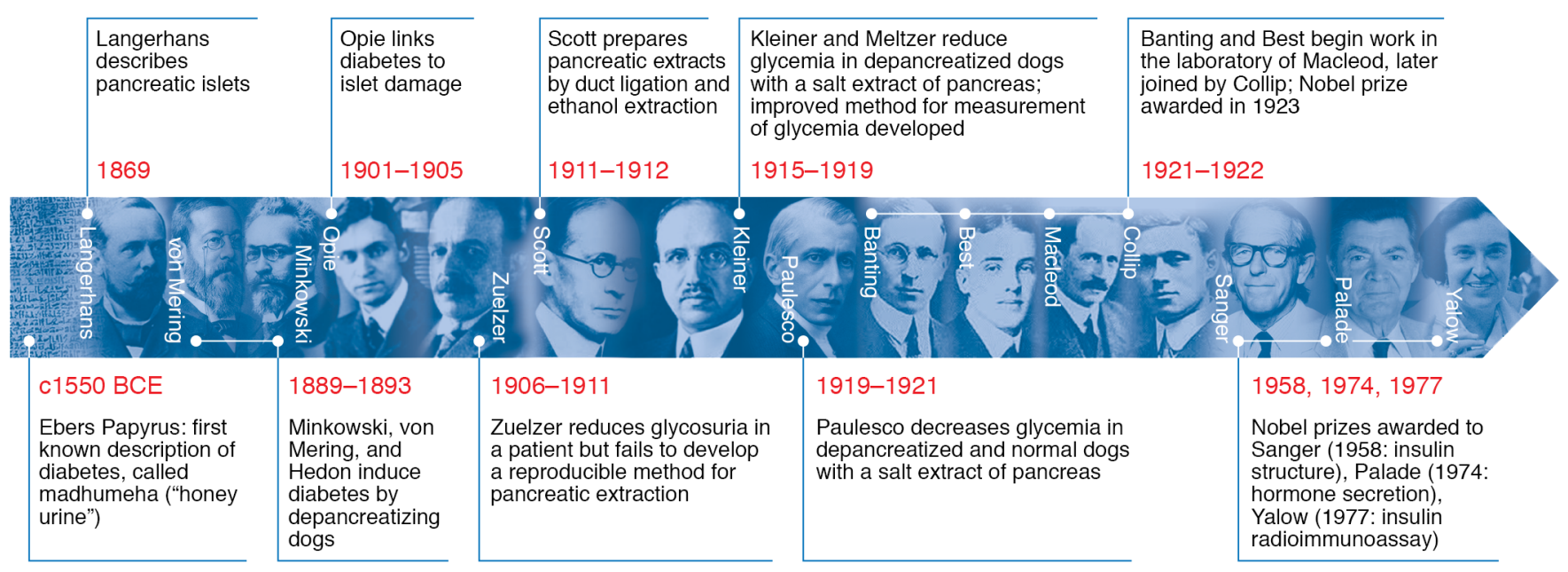

Figure 1. Timeline of notable advances in the discovery of insulin through history, showing some of the key players and their contributions.

mellitus. For example, Oscar Minkowski and Joseph von Mering in 1889, and Hédon in 1893, reproduced the diabetic state by pancreatectomizing dogs and hypothesized that this was due to loss of an "internal secretion" of the pancreas rather than of the pancreatic exocrine secretion $(4,5)$. They and many others subsequently performed experiments with crude pancreatic extracts, struggling with limited success to obtain a robust reduction in urinary glucose and ketones or to improve the well-being of diabetic animals, and even in some cases humans, without inducing major toxicity. Eugene Opie in 1901 showed a pathological connection between diabetes and damage to the islets of Langerhans (6), and many other investigators laid the groundwork for the discovery of insulin during the first two decades of the 20th century with important advances that revealed the workings of what came to be known as endocrine glands and hormones. In the first decade of the 20th century, there was ongoing, active research by numerous investigators (Zuelzer, Murlin, Scott [ref. 7], and others) to isolate a pancreatic, glucose-lowering factor (8-10). Indeed, between 1915 and 1919, Kleiner and Meltzer at the Rockefeller University published promising glucose-lowering results of their pancreatic extracts in depancreatized dogs $(11,12)$. Furthermore, a Romanian scientist, Nicolas Paulesco, published a series of important papers in 1921 describing successful experimentation with pancreatic extracts, which he called "pancréine" (13-17).

Michael Bliss (1), in his in-depth research of Banting's original notes and correspondence as well as of the accounts of others who interacted with Banting, paints a picture of a man who had a practical desire to get on with the work, a relative disinterest in research scholarship, a weak background of scientific knowledge, and inexperience at research, all of which militated against a careful, thorough study of the literature, including pertinent publications of the others who had gone after the internal secretion. Bliss goes on to comment that "if Banting and Best were aware of the work of Zuelzer and E.L. Scott, for example, they either did not bother to read their articles, which are not listed on their surviving index cards, or they decided there was no need to cite this work in their early publications" (1). Although Banting and Best do appear to have been aware of the results just published by Nicolas Paulesco of Romania, Bliss reports an interesting anecdote (1) that Best apparently mistranslated the French of Paulesco's paper, interpreting his use of the phrase "non plus," describing his results, as "not good" rather than "not only." Indeed, Banting and Best's neglect was not limited to the work of this one researcher, as they seem to have paid very little attention to almost anyone who had worked on pancreatic extracts before them. Notwithstanding the fact that failure to appropriately acknowledge the work of others is frowned upon in academic circles, the picture painted by Bliss (1) suggests that Banting and Best were not copying Paulesco but instead forging their own path. Shortly after the Toronto group's first successful clinical tests, Paulesco administered his extract to humans. He too used whole beef extracts but used a saline rather than an alcohol extraction and administered the extract rectally. Unfortunately, he achieved no demonstrable glucose-lowering effect. Paulesco continued testing his patented pancréine in dogs and occasionally in humans through 1922 but eventually abandoned his experiments (13-17).

\section{The Toronto researchers' breakthrough in isolating insulin}

So, what were the factors that allowed the Toronto group to succeed where many others had failed? First, one must acknowledge the sheer determination and perseverance of Banting and his junior assistant, Charles H. Best, an undergraduate student in physiology and biochemistry whom Macleod assigned to work with Banting, and who worked tirelessly with Banting throughout the entire summer of 1921 and the ensuing months (Figure 2). From the outset, it was clear that Banting was never simply a curious researcher studying physiology but intended to (in his own words) study the internal secretion of the pancreas and "if possible isolate it in a form that will be of use in treating Diabetes" $(1,2)$. Second, one must recognize the research expertise and resources that were provided to the research-naive Banting and Best by Macleod, who had a well-equipped, funded laboratory (18-21) and who provided experimental guidance, although the extent of the latter has been hotly debated on the grounds that, at the time that the critical canine experiments were performed in the summer of 1921, Macleod was visiting his native Scotland (1). Banting and 
A

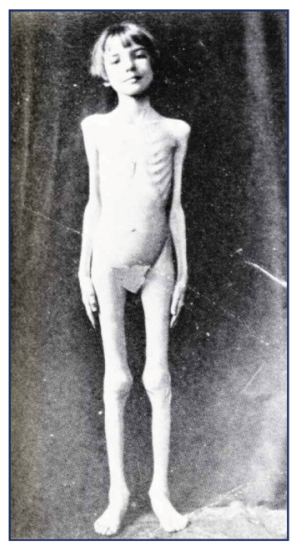

D

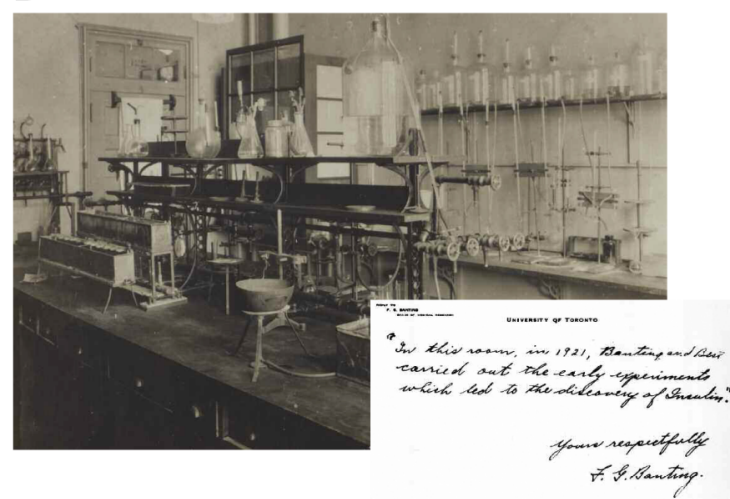

B

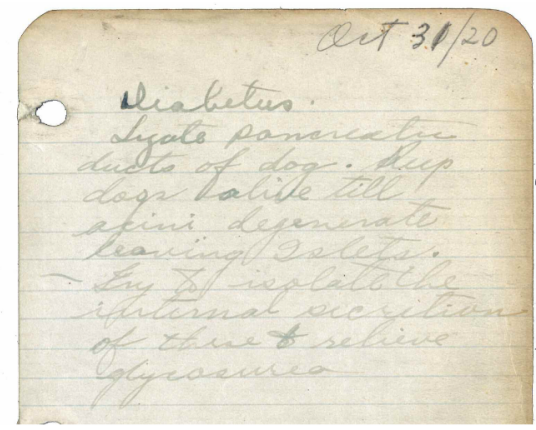

C

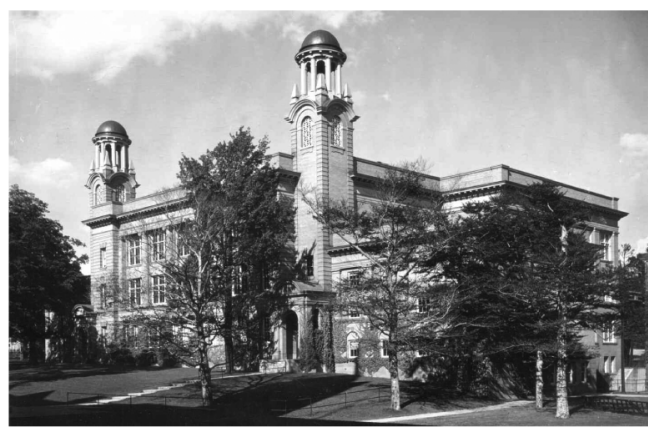

$\mathbf{F}$

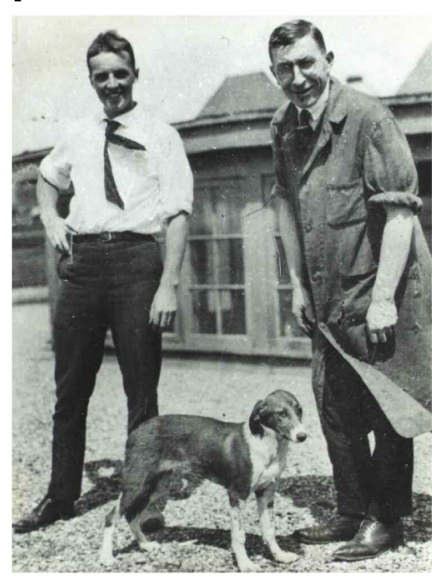

G

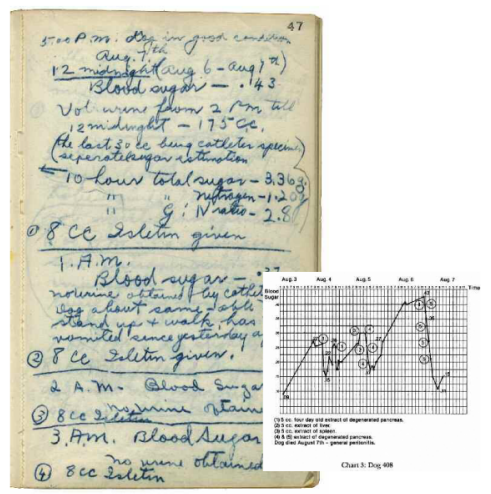

H

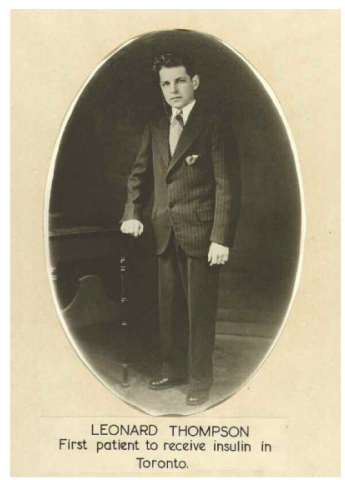

E

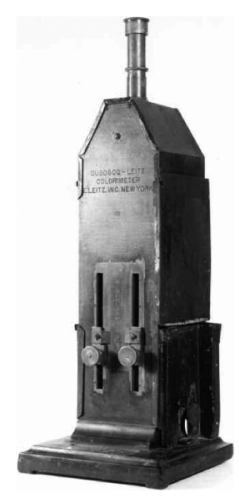

I

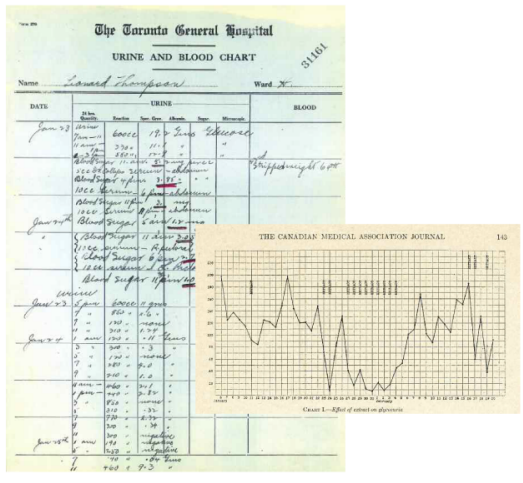

Figure 2. The discovery of insulin and the first human administration. (A) Young girl with type 1 diabetes, which, before 1921, was a death sentence. (B) The Toronto insulin story began on October 31, 1920, when Dr. Frederick Banting noted an idea for an experiment to isolate an internal secretion from the pancreas. (C) The Medical Building, University of Toronto, stood at the center of a uniquely linked group of medical and scientific institutions including the Toronto General Hospital and the University's public health biologicals producer, Connaught Laboratories. (D) Laboratory in which Banting and Best's experiments were performed. (E) Colorimeter for analyzing blood and urine glucose levels. (F) Charles Best (left) and Dr. Frederick Banting (right) with a dog on the roof of the Medical Building, August 1921. After meeting Dr. J.J.R. Macleod, Head of Physiology at U of T, Banting was given a lab, experimental dogs, and the assistance of undergraduate student Charles Best. Over the summer of 1921, their notebooks reported encouraging results with "Isletin" controlling blood sugar levels in depancreatized dogs. (G) Banting's notebook for August 7, 1921, and chart, showing first blood sugar reductions using "Isletin" in dog 408. (H) On January 11, 1922, a 14-year-old patient with type 1 diabetes, Leonard Thompson, was the first to receive an injection of the pancreatic extract, but with no effect. (I) On January 23, Thompson received a more purified extract with good results. This extract was developed by Dr. James Collip, a biochemist, who joined Banting and Best in December 1921. Images courtesy of The Thomas Fisher Rare Book Library, University of Toronto.

Best's initial crude and impure pancreatic extract did not employ purification methods that were more advanced than those of the many investigators who performed similar experiments over the preceding two decades. However, they did have one major exper- imental advantage: by 1921, advances in blood glucose analysis allowed them to monitor, using repeated measures on much smaller aliquots of blood, a far more precise biological readout of the effects of their pancreatic extract as compared with the tools 
A

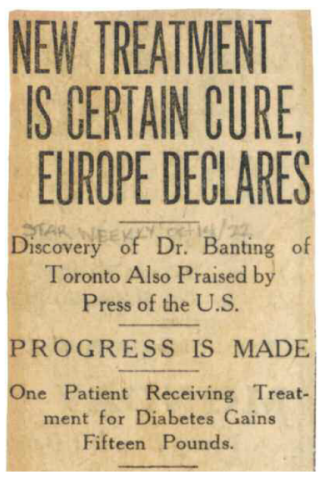

C

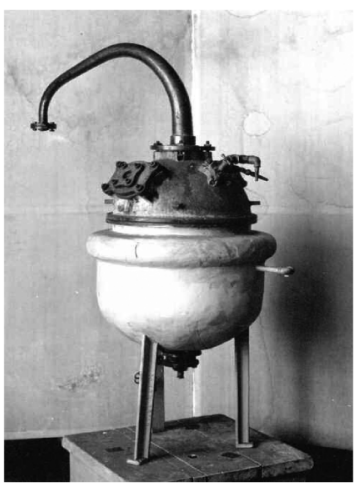

$\mathbf{F}$

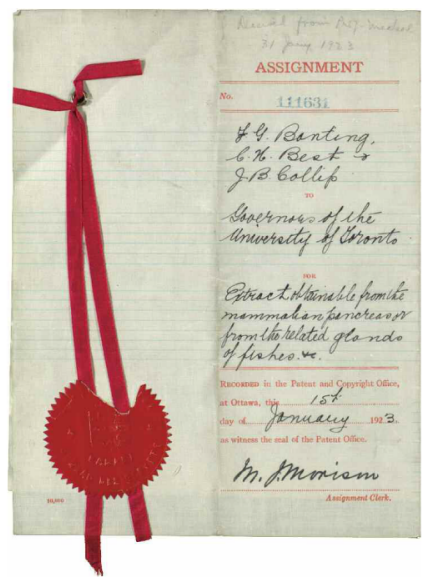

B
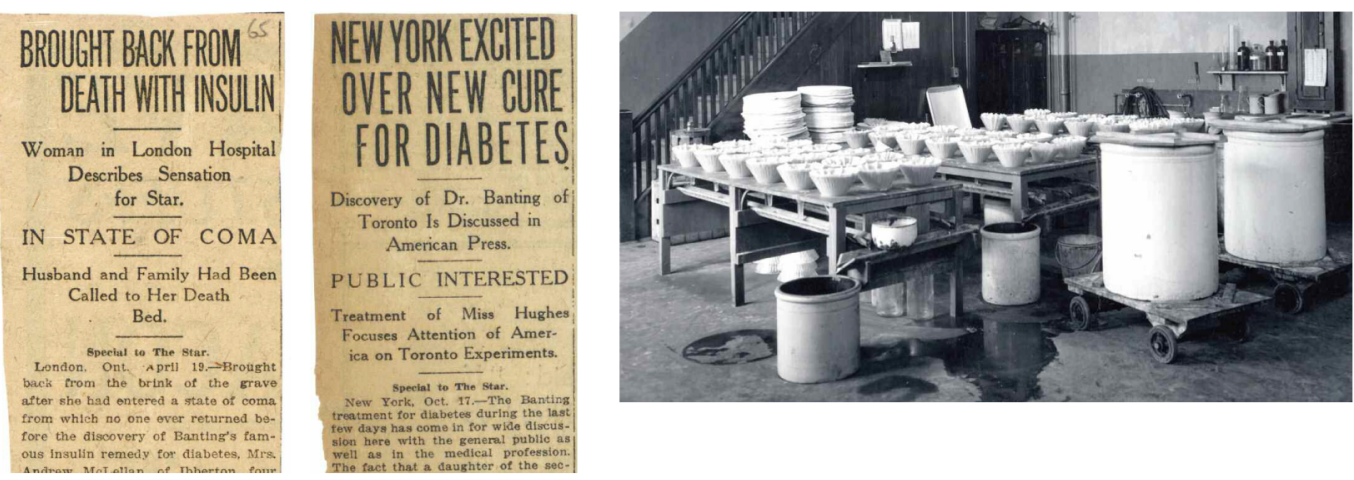

E
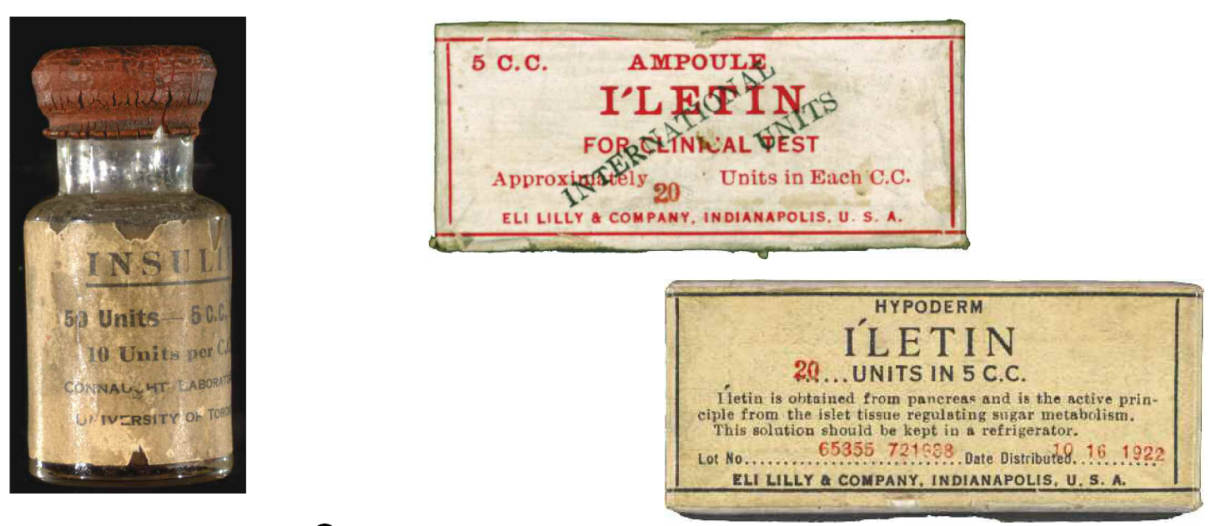

G
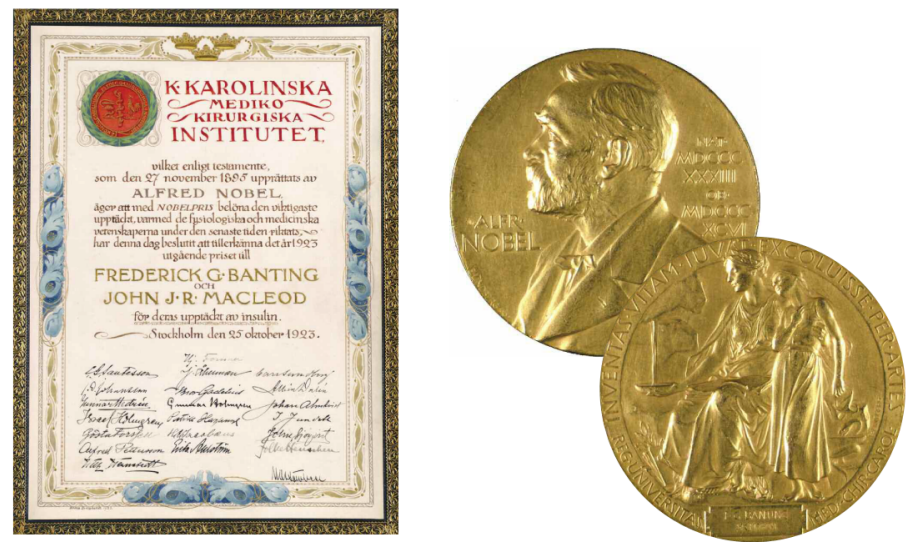

Figure 3. A Spreading Story: Excitement Grips the World! (A) Reports of insulin's first clinical trials in Toronto led to press coverage and a wave of requests for this diabetes "cure" from around the world. The severe insulin supply challenges during 1922 meant only a few critically ill patients could be treated. (B) Insulin production, Connaught Laboratories, University of Toronto, c. 1923. (C) Early vacuum still for insulin extraction. (D) Original vial of insulin produced by Connaught Laboratories, reproduced with permission from Sanofi Pasteur Canada (Connaught Campus) Archives. Connaught's larger insulin facility in the former YMCA Building at the University of Toronto opened in May 1923, starting a period of steady declines in insulin prices that continued until 1942. (E) Making enough insulin at lower prices and scaling up production to meet a growing need - Eli Lilly's Isletin insulin. Encouraged by Leonard Thompson's successful treatments, commercial agreements were developed to initiate large-scale production of the extract. The University of Toronto Insulin Committee granted Eli Lilly exclusive US rights until 1924, when other firms were granted licenses. (F) On January 1, 1923, to protect the discovery from the unscrupulous, Banting, Best, and Collip assigned the insulin patent to the University of Toronto, with proceeds dedicated to supporting medical research. (G) In 1923, the Nobel Prize in Physiology or Medicine was awarded to Banting and Macleod, who immediately shared their awards with Best and Collip, respectively. While there were tensions between Banting and Macleod, the Nobel experience highlighted that in the insulin story, there indeed was "glory enough for all" (1). Images courtesy of The Thomas Fisher Rare Book Library, University of Toronto.

available to previous researchers (22-24). Thus, although they were not the first to monitor blood glucose in response to injection of a crude pancreatic extract, the more precise analysis of blood glucose gave them a tremendous advantage in monitoring the effectiveness of their extracts. Additionally, Macleod was a rigorous experimentalist and an internationally recognized authority in 
carbohydrate metabolism (18-21) who demanded reproducibility and appropriate controls and, thus, complemented Banting's relative inexperience as a research scientist (1).

It is interesting to recount how Banting slowly came to abandon his central hypothesis that ligation of the pancreatic duct would result in degeneration of the exocrine pancreas. If allowed to interact with insulin in the pancreatic islets, the digestive enzymes produced by this tissue would render the insulin inactive, thereby preventing successful isolation of the "internal secretion" that was believed to lower blood sugar and potentially cure diabetes. In fact, Banting's gradual pivot away from the hypothesis that kick-started the entire Toronto research endeavor is rich in lessons for modern-day researchers. By late summer of 1921, a major impediment threatened to delay and potentially derail Banting and Best's exciting research. Specifically, the duct ligation method was slow (requiring a 4 - to 7 -week waiting period between duct ligation and harvesting of the degenerated pancreas); cumbersome, requiring Banting's expert surgical skills; and expensive. Delays in generating duct-tied dogs whose degenerated pancreata could be ground up to make "isletin" could thus result in long delays in obtaining supply of extract - particularly problematic because survival experiments requiring longevity in dogs were required. Impatient to continue their experiments, in late August 1921, the Toronto researchers made extracts from the pancreas of a healthy dog that had not undergone duct ligation. Using this extract, they achieved successful reduction in the blood sugar of a depancreatized, diabetic dog.

As researchers know, it takes tremendous discipline not to believe in one's hypothesis to the point that it could bias experimental results or to try to "prove" rather than objectively test a hypothesis (or, technically speaking, test the null hypothesis). The results of a well-performed experiment should contribute to the scientific body of knowledge regardless of whether the initial hypothesis was correct. Banting and Best, like so many researchers before and after them, fell into the trap of believing too avidly in their hypothesis that pancreatic duct ligation was critical to isolating an internal secretion that would effectively lower blood sugar. Hence, in their first publication, they wrote that "it is obvious from the chart (of the above experiment) that the whole gland extract is much weaker than that from degenerated gland" (25), although the figures in that paper suggest otherwise. However, still believing that it was necessary to get rid of the external secretions and running out of duct-ligated dogs, they tried repeated stimulation of pancreatic exocrine secretion using the duodenal enteroendocrine hormone secretin. Although this process succeeded in reducing the digestion of insulin during extraction, it was difficult as well as time-consuming owing to the initial requirement to isolate the secretin (1). In an additional study in October 1921, one duct-ligated dog pancreas was found to be only partly degenerated, so they prepared extracts from both the degenerated and the non-degenerated tissue. The extract from the less degenerated part was more effective, casting doubt on the hypothesis that a degenerated gland was necessary to produce a potent extract, a finding that, once again, the researchers seemed not to notice (1). Nonetheless, they continued experiments using extracts from only partially degenerated glands because of the reduced waiting period after the ligation.
In November 1921, Banting read Laguesse's paper showing that newborn and fetal animals have more plentiful islets in relation to the exocrine glands (26). Having been raised on a farm, he was aware that there would be plenty of fetal pancreata at the slaughterhouse, because cattle farmers "often bred their cattle just before slaughter to make them better feeders and fatter" (1). The experiments using extracts of fetal pancreas worked well, with the first diabetic dog tested demonstrating a complete absence of urinary glucose after only four injections $(1,27)$. Their success with fetal pancreas extracts led Banting and Best to wonder whether they could get a similar result from a fresh adult pancreas. On December 8, 1921, they performed a pancreatectomy on dog 35. Instead of discarding its pancreas, they purified the extract, injected it back into dog 35, and observed successful decline in blood glucose. Now the research would go forward using cheap, easily obtainable supplies of fresh whole pancreata.

An additional advance came when Banting and Best began to use alcohol in the preparation of their pancreatic extracts, an idea that Macleod had suggested months earlier and one that had been used more than 15 years previously by Scott $(1,10)$. James Bertram Collip, a young biochemist from the University of Alberta who was on sabbatical in Macleod's lab in 1921-1922, was assigned by Macleod in mid-December 1921 to make further improvements to the purity of the extract, with the goal of clinical administration (28). Collip had research experience in internal secretions and experience in making and injecting tissue extracts $(29,30)$. His contribution to the process was to optimize the alcohol extraction procedure so that the active principle (insulin) remained in solution, allowing precipitation of other protein contaminants and subsequent removal of lipids and salts by washing and centrifugation. Additionally, in late 1921, Collip began to use rabbits to determine the biological effectiveness of his increasingly purified extract, greatly increasing the speed and efficiency of experimentation in comparison with using dogs $(31,32)$. Collip was also the first to demonstrate repletion of hepatic glycogen content in response to his extract, thereby providing one of the mechanisms underlying the glucose-lowering actions of insulin (33).

Collectively, it is evident that the discovery of insulin could not have occurred without the combined efforts of Banting, Best, Collip, and Macleod. One could consider the work of Banting and Best as the first of two phases, providing definitive proof that pancreatic extracts contained a factor that could be used to treat diabetes, and Collip's work as the second phase, the purification (in a strict sense, not the isolation) of that factor from impurities that would cause a toxic reaction. And, finally, perhaps the most important factors that gave the Toronto group the edge were their drive and laser-like focus on developing a treatment for human diabetes. This largely originated from Banting, in collaboration with Best, who persevered as a team in the face of great odds. Whether due to naiveté on their part, to the reluctance of Banting to return to his struggling clinical practice in London, Ontario, and/or to the genuine excitement of scientific discovery, the ultimate result was the development of a pancreatic extract that successfully reduced glycemia and prolonged life in pancreatectomized dogs $(25,27,34)$. The active substance in the extracts was named "insulin" (from the Latin insula, meaning island, in reference to the islets of Langerhans) (35-37). 


\section{Early clinical use of insulin}

The first successful human administration of insulin was performed on January 23, 1922, at the Toronto General Hospital, to 14-year-old Leonard Thompson (this was Thompson's second administration of pancreatic extract, the first, on January 11 , having been largely ineffective) $(27,31)$. Before the treatment, Thompson was emaciated, weighing only 65 pounds, in ketoacidosis and desperately ill, lying listless in bed and close to death. His clinical response to the more purified extract, administered by clinician Walter Campbell, was rapid and dramatic. His glycosuria and ketonuria almost disappeared, and his blood sugar declined by approximately $75 \%$. Clinical notes indicate that "the boy became brighter, more active, looked better and said he felt stronger" (1). Leonard Thompson lived with type 1 diabetes for an additional 13 years after his initial treatments with insulin. Another early patient was 5-year-old Teddy Ryder (weighing 26 pounds at treatment onset), who was reported to have been transformed by insulin into "a vigorously healthy, happy boy with a round face and a thick mop of brown hair" $(1,38)$. Teddy Ryder died in 1993 at age 76, a few years after the authors had the privilege of meeting him as a robust and healthy-appearing gentleman. Another was Elizabeth Hughes (age 14, weighing 45 pounds at treatment onset), daughter of the US Secretary of State, who lived a "normal life" before dying of heart failure in $1981(1,38)$. Was this event the true "discovery" of insulin, or should that term be attributed to earlier investigators or, in fact, to later investigators who first isolated and crystalized insulin (39), determined its amino acid $(40,41)$ and gene $(42)$ sequences, engineered recombinant insulin $(43,44)$, and/or determined the crystal structure of the zinc-insulin hexamer (45)? What is beyond dispute is that Banting, Best, Collip, and Macleod were the first to develop an insulin preparation as an effective therapy for humans affected by diabetes, and no other investigators or groups can lay claim to that accomplishment (refs. 27, 31; and Figure 3). Their discovery of insulin was acknowledged by the awarding of the 1923 Nobel Prize in Physiology or Medicine to Frederick Grant Banting and John James Rickard Macleod, shared with Charles Best and James Collip, respectively (46).

\section{Commercialization of insulin}

What was the role of industry in the manufacture and distribution of insulin that made it widely available as rapidly as possible as a lifesaving therapy, and how did academia and industry interact? On January 25, 1921, two days after the first successful human administration of their pancreatic extract, Banting, Best, Collip, and Macleod signed an agreement of cooperation with the University of Toronto's wholly owned, noncommercial, public health entity Connaught Antitoxin Laboratories, established in 1914 to produce diphtheria antitoxin and located in the basement of the University of the Toronto Medical Building $(47,48)$. However, production of insulin in the Connaught Laboratories was insufficient to meet the increasing, and increasingly desperate, demand. By May 1922, attempts to scale up production of insulin had failed, and there was mounting pressure to take action to produce more insulin. Outside help was therefore urgently needed to circumvent the growing crisis $(1,47,48)$. G.H.A. Clowes, research director of Eli Lilly and Company based in Indianapolis, Indiana, first became aware of the Toronto group's work in late 1921. Clowes had been in communication with Macleod and had shown persistent interest in his firm's developing the new extract. In late May 1922, the University of Toronto and Eli Lilly worked out an agreement that gave Eli Lilly the exclusive rights to manufacture and distribute insulin (free of charge) to selected physicians and hospitals $(1,48,49)$. After one year, the company was free to charge for insulin and patent any innovations on their product (see also below). A very close working relationship between the Toronto team and scientists at Eli Lilly ensued (50, 51). The rationale provided by the board of governors of the University of Toronto for favoring one company was that concentrated effort by one firm would be the most effective solution to overcoming the supply problem. Heading off anticipated criticism of being "unethical or unfair or as in any way prejudicial to the free manufacture of insulin" (1), they also stated that they would "give other firms, as well as hospitals and other non-commercial concerns, every chance to do the best they can by publishing the details of the methods ... in full at an early date" $(1,48,49)$. With the resources and advances Lilly applied to the manufacture of their pork "Isletin" by late 1922, they were starting to overcome the drastic shortage. Further modifications overcame several potency and stability issues, and, by early 1923, Lilly was able to manufacture sufficient high-quality insulin for the needs of the entire world $(1,48,49)$. By late 1922, the Connaught Laboratories had updated their equipment and production facilities and also begun to overcome their initial production challenges $(1,47,48)$. The University of Toronto also granted complete British patent rights to the insulin extract to the Medical Research Council of Great Britain (48), and European rights to the nonprofit Nordisk Insulin Laboratory, facilitated by the Nobel laureate August Krogh of the University of Copenhagen and his associate, H.C. Hagedorn, later merging with Novo to become the present-day insulin manufacturing company Novo Nordisk (48).

Of the many questions that have arisen since 1921, one is why the Toronto scientists did not attempt to profit personally from their discovery. In fact, there is some evidence that the biochemist Collip considered patenting his purification method whereas Banting and Macleod, the two qualified physicians on the team, were reluctant to be associated with patenting on the ethical ground that commercialization might make their discovery unavailable on a widespread basis. Banting famously declared that "insulin does not belong to me, it belongs to the world" (52), and he turned down subsequent opportunities to profit personally from the discovery, consistent with his highly ethical belief that even the most financially destitute of patients should not be deprived of insulin by commercial forces $(1,48)$. However, their hand was forced when they became aware that a competitor's patent could interfere with their work in Toronto and could even, potentially, shut them down. Therefore, in April 1922, discussions began regarding patenting of the insulin purification method, with the formal sale/ transfer of their patent rights by Banting, Best, and Collip to the University of Toronto for \$1 apiece finalized in December 1922, followed by the University filing an application for a patent. They felt that providing their patent to the university would prevent their discovery from being commercially exploited by a single 
company. The justification for filing a patent was that "when the details of the method of preparation are published anyone would be free to prepare the extract, but no one could secure a profitable monopoly" (1). The University of Toronto received royalties in North America from the licensing of insulin, totaling \$8 million (Canadian dollars) between 1923 and 1967. In contrast, Eli Lilly sold more than a million dollars of insulin in just the first year of marketing, with additional and substantial profits also being realized by the other major pharmaceutical companies involved in the early production of insulin (1). The discovery of insulin thus provided a formative test case for the relationship between academia and industry (48), a relationship that has changed substantially over the past 100 years. Unlike today, when commercialization of medical discoveries is a point of pride for researchers and universities, in 1921 researchers and universities felt uneasy about profiting from medical discoveries that were, first and foremost, to benefit humanity. However, given the technical advances brought by industry to the insulin field since 1921 (human insulin and longand rapid-acting preparations, to name a few), it is difficult now to ascertain whether different decisions regarding the patenting of insulin would have altered the course of its clinical history.

One additional question arises as to the motivation of Banting to develop a treatment for diabetes. It is clear that he had no experience in treating patients with diabetes, and indeed it could be argued today that there were far more pressing medical issues in the world, owing to the H1N1 influenza pandemic of 1918-1920 (53). Many people who played roles in Banting's life are known to have contracted influenza, including Charles Best's fiancée, Margaret Mahon, in the winter of 1919 (54); Elizabeth Hughes, one of the earliest patients treated with insulin, in early 1919 (38); Sir William Osler, a medical "giant" in Canada, who died of related complications in December 1919 (55); and James Collip's family in early 1922 (1). However, in the long run, although influenza killed a devastating 50 to 100 million people worldwide (56), the death rate was lower (estimated as $8 \%-10 \%$ in young adults, the most affected age group; ref. 53 ) than that of type 1 diabetes, which affected far fewer individuals but had a death rate of $100 \%$; insulin was not a "cure for diabetes," but it prevented death. Whether these issues played any role in Banting's decision to pursue this area of research remains a matter of interesting speculation during the current SARS-CoV-2 (COVID-19) pandemic.

\section{The future of insulin therapy}

Although lifesaving, insulin treatment in its early days was primitive by today's standards and extremely difficult to administer for the person living with diabetes. Early treatment was plagued by shortages of supply and variable potency, and required large injected volumes (typically 3 to $7 \mathrm{~mL}$ ) that resulted in painful, sterile or infected, subcutaneous abscesses, frequent hypoglycemia, and suboptimal glycemic control (1) that, in the long term, increased the risk of the life-threatening or life-altering complications of nephropathy, circulatory problems, lower-extremity amputations, and blindness (57). Many advances in insulin treatment have been made over the years, including the development of modified insulins with both shorter and longer durations of action, the replacement of animal insulins with recombinant human insulin, improved insulin delivery devices (pens and infusion pumps), and improvements in glucose self-monitoring, including capillary glucose testing, the discovery of hemoglobin $\mathrm{A}_{1 \mathrm{c}}$ as a tool to monitor glycemic control, and, more recently, continuous glucose monitoring, not to mention numerous advances in prevention and treatment of diabetic complications (58). These advances over the past 100 years have had a real and tangible impact on the lives of persons affected by diabetes and have dramatically reduced all-cause mortality (59); however, profound limitations still remain. Frustratingly, we still have not perfected mechanisms for truly physiological insulin delivery. Insulin administered subcutaneously, even using sophisticated devices such as an insulin pump coupled with a continuous glucose monitor, remains an imperfect substitute for a healthy pancreas secreting insulin in response to multiple feedback loops, into the portal vein with first-pass through the liver (60). Tremendous effort is currently being directed to developing improved mechanical, closed-loop insulin delivery devices as well as cell-based insulin delivery therapies $(61,62)$.

However, many hurdles also remain in the prevention and treatment of diabetes because of high prices and poor availability. In the United States, the high price of insulin has been attributed to many factors, including (but not limited to) the large number of stakeholders in an increasingly complex supply chain and the limited number of manufacturers (63). The high cost of insulin has recently become a political issue in the US (64) but is also a global concern, with one in two people who need insulin lacking access, and the WHO Global Report on Diabetes (2016) stating that "people with diabetes who depend on life-saving insulin pay the ultimate price when access to affordable insulin is lacking" (64-66). Improvement of insulin availability and affordability needs to be addressed through national and global actions, including prioritizing the supply of more affordable human insulin, increasing competition through the use of lower-priced quality-assured biosimilars, negotiating lower prices from manufacturers, and improving distribution systems (66). It is disturbing to acknowledge that, throughout the world, insulin is still unavailable to millions of people in need.

It has now been 100 years since the discovery of insulin as a lifesaving therapy for patients with type 1 diabetes and as a component of the therapeutic regimen for those with type 2 diabetes. However, despite the remarkable advances made over the past century, many challenges remain for the person living with diabetes. It is the dream of every diabetes researcher to make a giant, leapfrogging advance that could, dare we say, cure diabetes. In the meantime, we continue to see incremental improvements in the lives of those living with diabetes based on the collective hard work of diabetes advocates, health policy experts, health care providers, educators, researchers, and clinicians working collaboratively on the most intractable problems.

\section{Acknowledgments}

We dedicate this article to Professor Michael Bliss, award-winning University of Toronto historian, who provided arguably the most comprehensive historical account in his 1982 book The Discovery of Insulin (1). Michael was excited about the upcoming 100th anniversary of the discovery of insulin, was in frequent contact with the authors, and very much wanted to participate in the celebrations. Sadly, he passed away in May 2017 at the age of 76, unable to realize that wish. 
GFL is the holder of the Sun Life Financial Chair and the Drucker Family Chair in Diabetes Research. PLB is supported by the Canada Research Chairs program. Studies on diabetes and lipoprotein metabolism in the Lewis laboratory are supported by an operating grant from the Canadian Institutes of Health Research (PJT-153301). Studies on diabetes in the Brubaker laboratory are supported by operating grants from the Canadian Institutes of Health Research (PJT-15308) and the Banting and Best Diabetes Centre, University of Toronto.

Address correspondence to: Gary F. Lewis, Toronto General Hospital, 200 Elizabeth Street, EN12-244, Toronto, Ontario, Canada M5G 2C3. Phone: 416.340.4270; Email: gary.lewis@uhn.ca.
1. Bliss M. The Discovery of Insulin. University of Toronto Press; 1982.

2. Bliss M. Banting: A Biography. McLelland and Steward Ltd.; 1984.

3. Jolles S. Paul Langerhans. J Clin Pathol. 2002;55(4):243.

4. Minkowski O. Historical development of the theory of pancreatic diabetes by Oscar Minkowski, 1929: introduction and translation by Rachmiel Levine. Diabetes. 1989;38(1):1-6.

5. Keck FS, Pfeiffer EF. The first experimental diabetes mellitus. Acta Diabetol Lat. 1989;26(1):79-81.

6. Opie EL. On the relation of chronic interstitial pancreatitis to the islands of Langerhans and to diabetes melutus. J Exp Med. 1901;5(4):397-428.

7. Department of Physiology. History of the Department. University of Toronto website. https:// www.physiology.utoronto.ca/historydepartment. Accessed October 28, 2020.

8. Zuelzer G. Pancreas preparation suitable for the treatment of diabetes. US patent 1027790A; 1912 (filed 1908). https://patents.google.com/patent/ US1027790A/en.

9. Murlin JR, Kramer B. The influence of pancreatic and duodenal extracts on the glycosuria and the respiratory metabolism of the depancreatized animal. Proc Soc Exp Biol Med. 1913;10(5):171-173.

10. Scott EL. On the influence of intravenous injections of an extract of the pancreas on experimental pancreatic diabetes. Am J Physiol Cell Physiol. 1912;29(3):306-310.

11. Kleiner I, Meltzer S. Retention in the circulation of dextrose in normal and depancreatized animals, and the effect of an intravenous injection of an emulsion of pancreas upon this retention. Proc Natl Acad Sci U S A. 1915;1(6):338-341.

12. Kleiner IS. The action of intravenous injection of pancreas emulsions in experimental diabetes. J Biol Chem. 1919;40:153-170.

13. Paulesco NC. Action de l'extrait pancréatique injecté dans le sang, chez un animal diabétique. CR Soc Biol. 1921;85(27):555-557.

14. Paulesco NC. Influence du laps de temps écoulé depuis l'injection intraveineuse de l'extrait pancréatique chez un animal diabétique. CR Soc Biol. 1921;85(27):558.

15. Paulesco NC. Influence de la quantité de pancreas employée pour préparer l'extrait injecté dans le sang, chez un animal diabétique. CR Soc Biol. 1921;85(27):558-559.

16. Paulesco NC. Action de l'extrait pancréatique injecté dans le sang chez un animal normal. $C R$ Soc Biol. 1921;85(27):559.

17. Paulesco NC. Recherche sur le rôle du pancréas dansl'assimilation nutritive. Arch Int Physiol. 1921;17:85-109.

18. Macleod JRR. Studies in experimental glycosuria - I. On the existence of afferent and efferent nerve fibres, controlling the amount of sugar in the blood. Am J Physiol Cell Physiol. 1907;XIX:388-407.

19. Macleod JRR. Various forms of experimental diabetes and their significance for diabetes mellitus. JAm Med Assoc. 1910;LV:2133-2138.

20. Macleod JRR. Recent work on the physiologic pathology of glycosuria. J Am Med Assoc. 1914;LXII:1222-1230.

21. Macleod JRR. Studies in experimental glycosuria - XII. Lactic acid production in the blood following the injection of alkaline solutions of dextrose or of the alkaline solutions alone. Am JPhysiol. 1917;XLII:460-468.

22. Pearce RG. A criticism of the Bang and LewisBenedict methods for the estimation of blood sugar, with suggestions for a modification of the latter method. J Biol Chem. 1915;22:525-533.

23. Myers VC, Bailey CV. The Lewis and Benedict method for the estimation of blood sugar, with some observations obtained in disease. J Biol Chem. 1916;24:147-161.

24. Schaffer PA, Harmann AF. The iodometric determination of copper and its use in sugar analysis, II: methods for the determination of reducing sugars in blood, urine, milk, and other solutions. J Biol Chem. 1920-1921;45:365-390.

25. Banting FG, Best CH. The internal secretion of the pancreas. 1922. Indian JMed Res. 1922;VII(5):251-266.

26. Laguesse E. Récherches sur l'histogénie du pancréas chez le mouton, III Origine et evolution des ilots de Langerhans (pseudo-follicules). J Anat Physiol. 1896;32:209-255.

27. Banting FG, Best CH, Collip JB, Campbell WR, Fletcher AA. Pancreatic extracts in the treatment of diabetes mellitus. Preliminary report. Can Med Assoc J. 1922; XII(3):141-146.

28. 100 Years of Biochemistry at U of T. University of Toronto website. http://biochemistry.utoronto. ca/wp-content/uploads/2018/09/100-years-ofbiochemistry-at-U-of-T-Packhmam-2008-1.pdf. Accessed October 28, 2020.

29. Macallum AB, Collip JB. A new substance in nerve cells. Rep Brit Assoc Advanc Sci. 1916;83:673-674.

30. Collip JB. Internal secretions. Can Med Assoc J. 1916;6(12):1063-1069.

31. Banting FG, Best CH, Collip JB, Fletcher AA, Macleod JJR, Noble EC. The effect produced on diabetes by extracts of pancreas. Trans Assoc Am Physicians. 1922;XXXVII:337-347.

32. Banting FG, Best CH, Collip JB, Macleod JJR, Noble EC. The effect of pancreatic extract (insulin) on normal rabbits. Am J Physiol. 1922;62(1):162-176.

33. Collip JB. History of the discovery of insulin. Northwest Med. 1923;22:267-273.

34. Banting FG, Best CH, Macleod JJR. The internal secretion of the pancreas. Am JPhysiol.

\section{2;LIX:479.}

35. Macleod JRR. Insulin. Physiol Rev. 1924;4(1):21-68.

36. De Meyer J. Action de la sécrétion interne du pancréas sur différents organes et en particulier sur la sécrétion rénale. Arch Fisiol. 1909;7:96-99.

37. Schäfer EA. An introduction to the study of the endocrine glands and internal secretions: Lane Medical Lectures, 1913. Stanford University; 1914.

38. Cooper TA, Ainsburg A. Breakthrough: Elizabeth Hughes, the Discovery of Insulin, and the Making of a Medical Miracle. St. Martin's Press; 2010.

39. Mirsky IA, Jinks R, Perisutti G. The isolation and crystallization of human insulin. J Clin Invest. 1963;42(12):1869-1872.

40. Sanger F. Sequences, sequences, and sequences. Annu Rev Biochem. 1988;57:1-28.

41. Nicol DS, Smith LF. Amino-acid sequence of human insulin. Nature. 1960;187:483-485.

42. Bell GI, Pictet RL, Rutter WJ, Cordell B, Tischer E, Goodman HM. Sequence of the human insulin gene. Nature. 1980;284(5751):26-32.

43. Crea R, Kraszewski A, Hirose T, Itakura K. Chemical synthesis of genes for human insulin. Proc Natl Acad Sci U S A. 1978;75(12):5765-5769.

44. Goeddel DV, et al. Expression in Escherichia coli of chemically synthesized genes for human insulin. Proc Natl Acad Sci U S A. 1979;76(1):106-110.

45. Smith GD, Swenson DC, Dodson EJ, Dodson GG, Reynolds CD. Structural stability in the 4-zinc human insulin hexamer. Proc Natl Acad Sci U S A. 1984;81(22):7093-7097.

46. The Nobel Prize in Physiology or Medicine 1923. Nobel website. www.nobelprize.org/prizes/ medicine/1923/summary/. Accessed October 28, 2020.

47. Rutty CJ. "Couldn't live without it": diabetes, the costs of innovation and the price of insulin in Canada, 1922-1984. Can Bull Med Hist. 2008;25(2):407-431.

48. Cassier M, Sinding C. 'Patenting for the public interest': administration of insulin patents by the University of Toronto. Hist Technol. 2008;24(2):153-171.

49. Malone JK, et al. Eli Lilly and company insulins a century of innovation. Pediatr Endocrinol Rev. 2020;17(S1):138-160.

50. Swann JP. Insulin. A case study in the emergence of collaborative pharmacomedical research. Part I. Pharm Hist. 1986;28(1):3-13.

51. Swann JP. Insulin. A case study in the emergence of collaborative pharmacomedical research. Part II. Pharm Hist. 1986;28(2):65-74.

52. Sir Frederick Banting, MD. Canadian Medical Hall of Fame website. https://www.cdnmedhall. org/inductees/frederickbanting. Accessed October 28, 2020

53. Barry JM. The Great Influenza: The Story of the Deadliest Pandemic in History. Viking Penguin; 2004. 
54. Best HBM. Margaret and Charlie: The Personal Story of Dr. Charles Best, the Co-Discoverer of Insulin. Dundurn Press; 2003.

55. Barondess JA. A case of empyema: notes on the last illness of Sir William Osler. Trans Am Clin Climatol Assoc. 1975;86:59-72.

56. Johnson NP, Mueller J. Updating the accounts: global mortality of the 1918-1920 "Spanish" influenza pandemic. Bull Hist Med. 2002;76(1):105-115.

57. Nathan DM, et al. The effect of intensive treatment of diabetes on the development and progression of long-term complications in insulin-dependent diabetes mellitus. N Engl JMed. 1993;329(14):977-986.

58. Science. Progress. Hope. Diabetes Timeline. American Diabetes Association website. https://www.diabetes.org/resources/timeline. Accessed October 28, 2020.

59. Rawshani A, et al. Mortality and cardiovascular disease in type 1 and type 2 diabetes. $N$ Engl J Med. 2017;376(15):1407-1418.

60. Matteucci E, Giampietro O, Covolan V, Giustarini D, Fanti P, Rossi R. Insulin administration: present strategies and future directions for a noninvasive (possibly more physiological) delivery. Drug Des Devel Ther. 2015;9:3109-3118.

61. Fuchs J, Hovorka R. Closed-loop control in insulin pumps for type-1 diabetes mellitus: safety and efficacy. Expert Rev Med Devices. 2020;17(7):707-720.

62. Nair GG, Tzanakakis ES, Hebrok M. Emerging routes to the generation of functional beta-cells for diabetes mellitus cell therapy. Nat Rev Endocrinol. 2020;16(9):707-720.
63. Cefalu WT, et al. Insulin access and affordability working group: conclusions and recommendations. Diabetes Care. 2018;41(6):1299-1311.

64. Fralick M, Kesselheim AS. The U.S. insulin crisis - rationing a lifesaving medication discovered in the 1920s. N Engl J Med. 2019;381(19):1793-1795.

65. World Health Organization. Global Report on Diabetes. WHO website. https://apps.who.int/iris/ bitstream/hadle/10665/204871/9789241565257 eng.pdf;jsessionid=234F77CBD8E83370046 ED8E8DEF9D153?sequence=1. Accessed October 28, 2020.

66. Ewen M, Joosse HJ, Beran D, Laing R. Insulin prices, availability and affordability in 13 lowincome and middle-income countries. BMJ Glob Health. 2019;4(3):e001410. 